\title{
Creep Deformation of Intermetallic TiAl-Based Alloy
}

\author{
J. LAPIN* AND H. STANEKOVÁ \\ Institute of Materials and Machine Mechanics, Slovak Academy of Sciences \\ Račianska 75, 83102 Bratislava, Slovak Republic
}

\begin{abstract}
In the present work, the creep deformation behaviour of a new cast intermetallic Ti-46Al-8Ta [at.\%] alloy is analysed. Constant load tensile creep tests were performed at initial applied stresses ranging from 200 to $400 \mathrm{MPa}$ in the temperature range from 973 to $1073 \mathrm{~K}$. The measured creep deformation curves are analysed and the observed deviations from calculated curves are discussed based on microstructural changes observed in the studied alloy during creep. The kinetics of creep deformation are evaluated in terms of the true activation energy for creep and the stress exponent. Creep damage initiation and propagation leading to the fracture of the creep specimens are characterized as functions of the applied stress and temperature.
\end{abstract}

PACS: 61.72.-y, 62.20.F-, 81.30.Mh, 83.50.-v

\section{Introduction}

Modern aero-engines and their key components are expected to respond extreme requirements concerning reliability, minimum weight, high performance, cost-efficiency, durability, reduced noise, and pollutant emissions. Recent efforts in the development of new low-weight intermetallic TiAl-based materials for low pressure turbine blades has led to the design of a new Ti-46Al-8Ta [at.\%] alloy [1, 2]. This so called "air-hardenable" alloy requires only free-air cooling from the single $\alpha$ phase (Ti-based solid solution with hexagonal crystal structure) field to reduce the grain size via the formation of massive $\gamma_{\mathrm{M}}(\mathrm{TiAl})$ during heat treatments. Contrary to many TiAl-based alloys with a well aligned lamellar $\alpha_{2}\left(\mathrm{Ti}_{3} \mathrm{Al}\right)+\gamma(\mathrm{TiAl})$ microstructure formed by precipitation of $\gamma$ lamellae from the $\alpha$ phase [3], heat treatment of $\mathrm{Ti}-46 \mathrm{Al}-8 \mathrm{Ta}$ (at.\%) results in a "convoluted" $\alpha_{2}+\gamma$ microstructure. The convoluted microstructure is formed by precipitation of the $\alpha$ and/or $\alpha_{2}$ phases on four equivalent $\{111\}$ planes of the massively transformed $\gamma_{\mathrm{M}}$ during annealing and subsequent cooling from the two-phase $\alpha+\gamma$ field [2]. This new alloy shows promising castability and has a relatively large processing window to achieve the $\alpha_{2}+\gamma$ microstructure during the heat treatments. However, its potential industrial applications are conditioned by optimisation of processing techniques [4,5], understanding of long-term high temperature microstructure stability $[6,7]$ and complex characterisation of mechanical properties [8].

The aim of the present work is to study the creep deformation of cast intermetallic Ti-46Al-8Ta (at.\%) at re-

\footnotetext{
* corresponding author; e-mail: umms lapi@savba.sk
}

alistic operating temperatures. Understanding the creep deformation is of primary importance as a major use of this alloy is assumed to be in low pressure turbine blades of aero-engines.

\section{Experimental procedure}

Cylindrical Ti-46Al-8Ta [at.\%] bars with a diameter of $13 \mathrm{~mm}$ and length of $120 \mathrm{~mm}$ were prepared from a plasma melted ingot prepared by IRC Birmingham [9] using centrifugal casting into ceramic moulds at ACCESS e.V. [10]. The cast bars were subjected to thermomechanical heat treatment consisting of hot isostatic pressing (HIP) at an applied pressure of $200 \mathrm{MPa}$, temperature of $1533 \mathrm{~K}$ for $4 \mathrm{~h}$, which was followed by solution annealing at $1633 \mathrm{~K}$ for $1 \mathrm{~h}$ and air cooling. The heat treatment was finalized by HIP ageing at an applied pressure of $150 \mathrm{MPa}$ and temperature of $1533 \mathrm{~K}$ for $2 \mathrm{~h}$ followed by cooling at a rate of $5 \mathrm{~K} / \mathrm{min}[6]$.

Cylindrical creep specimens with a gauge diameter of $6 \mathrm{~mm}$, gauge length of $30 \mathrm{~mm}$ were lathe machined from the as-received bars and the surface of their gauge section was polished using a diamond paste to a roughness of about $0.3 \mu \mathrm{m}$. Creep tests were performed in the temperature range from 973 to $1073 \mathrm{~K}$ at initial applied stresses ranging from 200 to $400 \mathrm{MPa}$. The specimen displacement was measured using a high-temperature extensometer attached to the ledges of the specimen. Continuous acquisition of time-elongation data was accomplished by a computer.

Microstructural evaluation of creep specimens was performed before and after testing by backscattered scanning electron microscopy (BSEM) and transmission electron microscopy (TEM). Metallographic preparation of samples consisted of standard grinding and polishing. 
TEM samples were mechanically thinned to a thickness of about $50 \mu \mathrm{m}$. The thinning continued in a solution of $300 \mathrm{ml} \mathrm{CH} 3 \mathrm{OH}, 175 \mathrm{ml}$ 2-butanol and $30 \mathrm{ml} \mathrm{HClO}_{4}$ at a temperature of $263 \mathrm{~K}$ and voltage of $40 \mathrm{~V}$ until the sample perforation. The volume fraction of coexisting phases and size of lamellar colonies were determined using a computer image analyser.

\section{Results and discussion}

Figure 1 shows the typical microstructure of Ti-46Al-8Ta [at.\%] alloy before creep. The convoluted $\alpha_{2}+\gamma$ microstructure consists mostly of plate-like $\alpha_{2}$ which forms small colonies within the $\gamma$ phase [11]. Mean length and average volume fraction of the $\alpha_{2}$ laths are measured to be $(8.5 \pm 0.3) \mu \mathrm{m}$ and $(29.8 \pm 1.3)$ vol.\%, respectively. Besides the continuous $\alpha_{2}$ and $\gamma$ lamellae, some single-phase $\alpha_{2}$ and $\gamma$ grains have been identified in the microstructure. Before creep the dislocations were heterogeneously distributed within the individual grains. Some $\gamma$ grains and $\gamma$ lamellae contained numerous dislocations while other grains were nearly free of dislocations. The high dislocation density within some grains when compared to low dislocation density usually observed in some TiAl-based alloys with lamellar $\alpha_{2}+\gamma$ microstructure $[12,13]$ can be explained by hot isostatic pressing at $1533 \mathrm{~K}$, which was applied to form convoluted $\alpha+\gamma$ microstructure during the heat treatments [11].

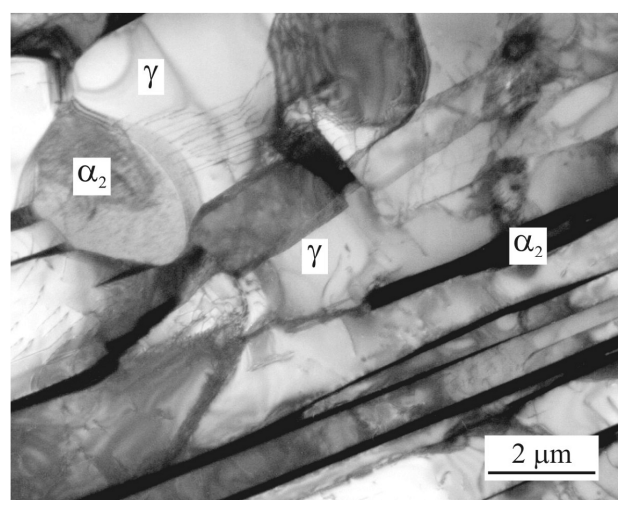

Fig. 1. TEM micrograph showing the typical microstructure of the $\mathrm{Ti}-46 \mathrm{Al}-8 \mathrm{Ta}$ [at.\%] alloy before creep.

All of the creep curves obtained in this study have the same basic shape, as shown in Fig. 2. The creep curves exhibit a short primary creep stage that is directly followed by tertiary creep. During the primary creep stage the creep rate decreases with increasing strain. After reaching a minimum at a true strain ranging from 1.2 to $3.5 \%$, the true creep rate increases with increasing strain. No steady-state creep stage was observed in the tests performed between 973 and $1073 \mathrm{~K}$ with applied stresses ranging from 200 to $400 \mathrm{MPa}$. The minimum creep rates $\dot{\varepsilon}_{\text {min }}$ and applied stresses $\sigma$ were fitted to the power law

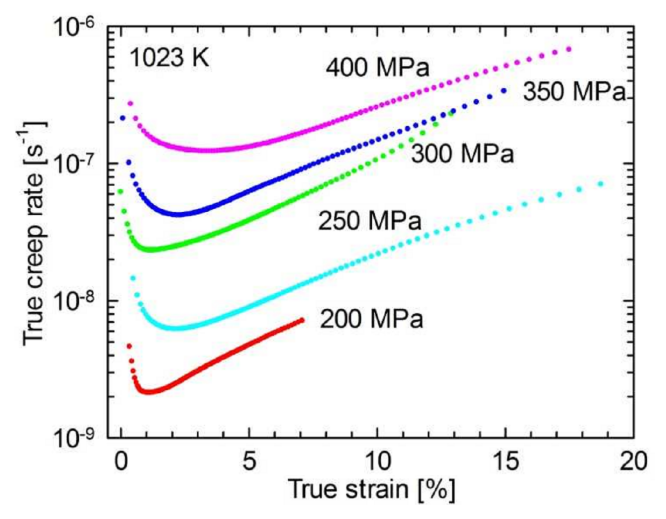

Fig. 2. Dependence of true creep rate on true strain at $1023 \mathrm{~K}$. The applied stresses are indicated in the figure.

$$
\dot{\varepsilon}_{\min }=A\left(\frac{\sigma}{G}\right)^{n}
$$

where $A$ is a constant, $G$ is the shear modulus at the relevant temperature and $n$ is the stress exponent. The temperature dependence of the shear modulus was determined experimentally from measured temperature dependence of the elastic modulus in the form $G=79.09-$ $0.016 T$, where $G$ is in GPa and $T$ is the absolute temperature in K. Using linear regression analysis of the creep data, the stress exponent $n$ is determined to vary from 5.6 to 6 . The stress-minimum creep rate-temperature data were also fitted to the power law expression

$$
\dot{\varepsilon}_{\text {min }}=B\left(\frac{\sigma}{G}\right)^{n} \exp \left(-\frac{Q}{R T}\right),
$$

where $B$ is a constant, $Q$ is the true activation energy for creep and $R$ is the universal gas constant. Taking $n=5.8$, one can calculate $Q=(360.4 \pm 12.5) \mathrm{kJ} / \mathrm{mol}$. Figure 3 shows the minimum creep rate normalised by an exponential term including the true activation energy for creep, the absolute temperature and the universal gas constant as a function of the applied stress normalised by the shear modulus. From this figure, it is obvious that all creep data over the studied temperature range and applied stresses cluster around a straight line. Regression analysis of the creep data yields an equation for the minimum creep rate in the form

$$
\dot{\varepsilon}_{\min }=1.485 \times 10^{24}\left(\frac{\sigma}{G}\right)^{5.8} \exp \left(-\frac{360400 \mathrm{~J} / \mathrm{mol}}{R T}\right) .
$$

The correlation coefficient $r^{2}$ of this fit is 0.98 . The measured stress exponent of $n=(5.8 \pm 0.2)$ can be compared with literature data for various TiAl-based alloys where values ranging from about 2 at low stresses to about 10 at high stresses are reported [11-18]. It should be noted that the stress exponent of 5.8 measured in this study is lower than that of 6.8 reported by Recina et al. [15] for $\mathrm{Ti}-48 \mathrm{Al}-2 \mathrm{~W}-0.5 \mathrm{Si}$ [at.\%] or that of $n=7.3$ determined by Lapin and Nazmy [16] for Ti-46Al-2W-0.5Si [at.\%] with a pseudoduplex microstructure. On the other 
hand, it is higher than the value $n=5$ determined by Parthasarathy et al. [17] for selected polycrystalline fully lamellar TiAl-based alloys or by Lapin [13] for Ti-45.2Al$2 \mathrm{~W}-0.6 \mathrm{Si}-0.7 \mathrm{~B}$ [at.\%].

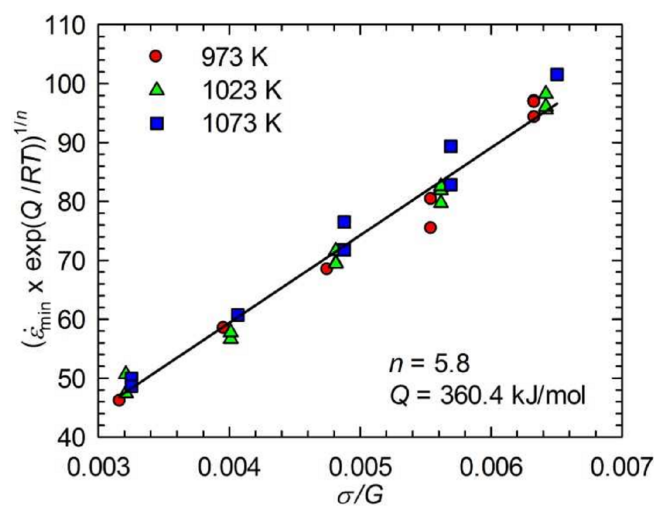

Fig. 3. Minimum creep rate normalised by the true activation energy for creep $Q$, universal gas constant $R$, absolute temperature $T$ and stress exponent $n$ as a function of the applied stress $\sigma$ normalised by the shear modulus $G$. The creep temperatures are indicated in the figure.

For the activation energy for creep, we can refer to the values ranging from 230 to $430 \mathrm{~kJ} / \mathrm{mol}$ reported in the previous studies. The true activation energy for creep of $Q=360.4 \mathrm{~kJ} / \mathrm{mol}$ is higher than that of $288-312 \mathrm{~kJ} / \mathrm{mol}$ and lower than $395 \mathrm{~kJ} / \mathrm{mol}$ determined for self-diffusion of $\mathrm{Ti}$ and $\mathrm{Al}$ in $\mathrm{Ti}_{3} \mathrm{Al}$, respectively [19]. For self-diffusion of $\mathrm{Ti}$ and $\mathrm{Al}$ in $\mathrm{TiAl}$, we can refer to the values of 250 $295 \mathrm{~kJ} / \mathrm{mol}$ and $358 \mathrm{~kJ} / \mathrm{mol}$, respectively [19].

During constant load creep tests, the gauge cross-sectional area of the specimen reduces in such a way that the true stress increases causing an increase of the true creep rate. Assuming that the reduction is homogeneous, which is a good approximation during the initial stages of deformation, the true stress $\sigma_{\mathrm{t}}$ increases with strain $\varepsilon$ according to relationship

$$
\sigma_{\mathrm{t}}=\sigma \exp (\varepsilon) \text {. }
$$

Figure 4 shows typical examples of variation of the true creep rate with the true stress at $1023 \mathrm{~K}$. In this figure, the black solid line represents the interpolation of minimum creep rate as a function of the true stress according to the Norton power law. The solid line represents the expected increase of the true creep rates as a consequence of the increase of the true stress $\sigma_{\mathrm{t}}$ supposing that no creep damage mechanism is operative. However, significant deviations of the experimental true creep rates from the Norton line are observed for all applied stresses. The stress exponent $n$ determined for the tertiary creep regimes increases from 14.4 to 21.7 with decreasing applied stress from 400 to $200 \mathrm{MPa}$. These stress exponents are significantly higher than the Norton power law exponent of $n=5.6$ determined for the minimum creep rates. The measured deviation of the true creep rates from the Norton power law can be attributed to microstructure changes of the studied alloy during creep. X-ray diffraction analysis of the crept specimens revealed that the initial convoluted $\alpha_{2}+\gamma$ microstructure is thermodynamically unstable and transforms to the $\alpha_{2}+\gamma+\tau$ during creep [11]. The particles of the $\tau$ phase with slightly variable chemical composition of $\mathrm{Ti}-$ (36-40)Al-(12-15)Ta [at.\%], B8 2 type of structure (space group $\mathrm{P}_{3} / m m c$, Pearson symbol $h \mathrm{P} 6$ ) and $\mathrm{Ni}_{2}$ In symmetry were identified recently by Lapin et al. [6, 7]. Particles of the $\tau$ phase are preferentially formed along the grain and lamellar colony boundaries at the expense of the $\alpha_{2}$ laths, which partially transform to a combination of the $\gamma$ matrix and $\tau$ particles.

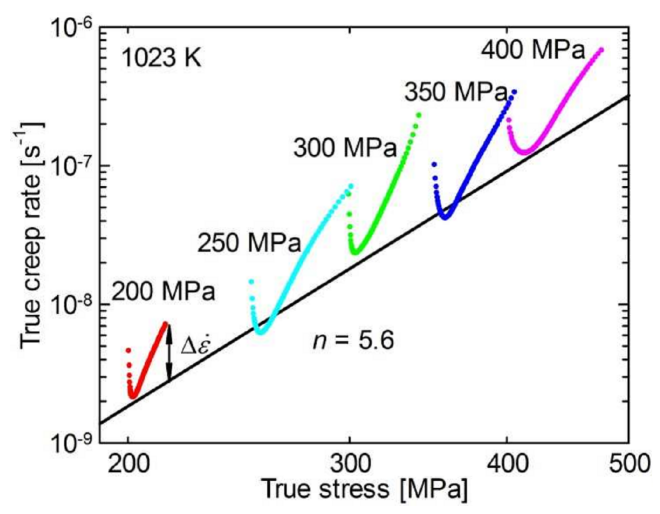

Fig. 4. Dependence of true creep rate on true stress at $1023 \mathrm{~K}$. The applied stresses are indicated in the figure.

During tertiary creep the specimens exhibited a plastic deformation ranging from $2.7 \%$ at $973 \mathrm{~K} / 250 \mathrm{MPa}$ to $24.4 \%$ at $1073 \mathrm{~K} / 350 \mathrm{MPa}$. At lower applied stresses of $200-300 \mathrm{MPa}$, tertiary creep is accompanied by nucleation and growth of cavities along the lamellar colony and grain boundaries, as shown in Fig. 5. The number and size of cavities is significantly higher in a macroscopically necked region of some creep specimens characterised by a reduction of the cross-sectional area ranging from $5 \%$ at $973 \mathrm{~K}$ to $13 \%$ at $1073 \mathrm{~K}$.

The deformation of TiAl-based materials with a lamellar microstructure depends strongly on grain orientation. The grains with the lamellae that are parallel or perpendicular to the stress axis are referred to as being in the "hard" orientation, whereas grains with the lamellae between $30^{\circ}$ and $70^{\circ}$ to the stress axis in a "soft" orientation [20]. At higher applied stresses of 350 and $400 \mathrm{MPa}$ and at all test temperatures, the tertiary creep regime is accompanied predominantly by the nucleation and growth of cracks and to a lesser extent by the nucleation and growth of cavities.

Figures 6 shows the orientation of cracks formed within the gauge section of the specimens crept at the highest applied stress of $400 \mathrm{MPa}$. Most cracks are formed at the grain boundaries inclined to load direction and some cracks passed transversally the grains and lamellae perpendicularly to the load direction. 


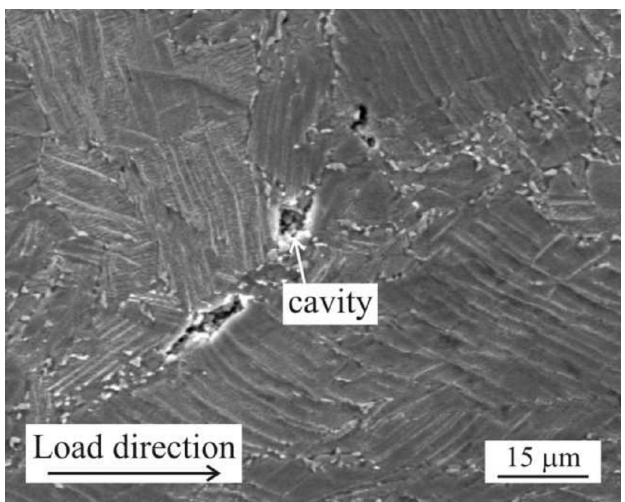

Fig. 5. BSEM micrograph showing formation of cavities on the longitudinal section of the gauge region of the creep specimens tested to fracture at $1073 \mathrm{~K} / 200 \mathrm{MPa}$ for $417 \mathrm{~h}$

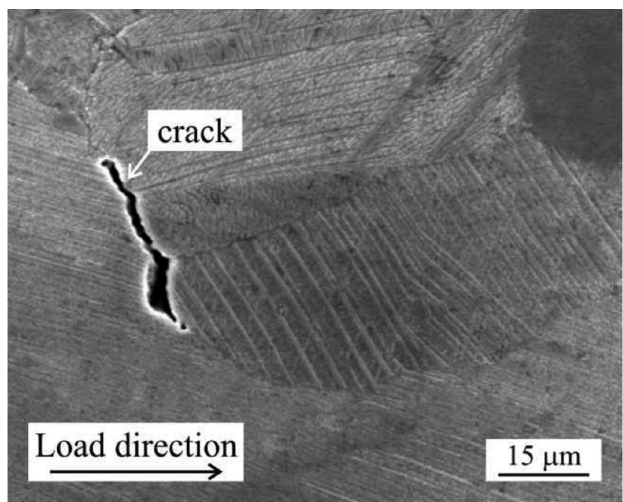

Fig. 6. BSEM micrograph showing formation of cracks on the longitudinal section of the gauge region of the creep specimens tested to fracture at $973 \mathrm{~K} / 400 \mathrm{MPa}$ for $1230 \mathrm{~h}$.

\section{Conclusions}

Creep deformation behaviour of a new cast intermetallic Ti-46Al-8Ta [at.\%] alloy was analysed. After a primary creep stage and then reaching a minimum value, the creep rate increases with increasing strain. The power law stress exponent for the minimum creep rates is measured to be 5.8 and the true activation energy for creep is $360.4 \mathrm{~kJ} / \mathrm{mol}$. The analysis of creep deformation curves in coordinates of true stress-true creep rates revealed significant deviation from the Norton power law. These differences can be related to instabilities of the initial $\alpha_{2}+\gamma$ microstructure which transforms to $\alpha_{2}+\gamma+\tau$ during creep. At lower applied stresses, the tertiary creep stage is accompanied by nucleation and growth of cavities along the lamellar colonies and grain boundaries. At higher applied stresses, the tertiary creep regime is ac- companied predominantly with nucleation and growth of cracks and to a lesser extent with the nucleation and growth of cavities.

\section{Acknowledgments}

This work was financially supported by the Slovak Research and Development Agency under the contracts APVV-0434-10 and APVV-0009-07 and the Slovak Grant Agency for Science under the contract VEGA $2 / 0157 / 10$. The authors would like to thank to U. Hecht from ACCESS (Germany) for providing the experimental material.

\section{References}

[1] D. Hu, A.J. Huang, X. Wu, Intermetallics 15, 327 (2007).

[2] H. Saage, A.J. Huang, D. Hu, M.H. Loretto, X. Wu, Intermetallics 17, 32 (2009).

[3] J. Lapin, Z. Gabalcová, O. Bajana, Kovove Mater. 47, 159 (2009).

[4] J. Lapin, K. Frkán̆ová, Kovove Mater. 49, 243 (2011).

[5] J. Aguilar, A. Schievenbusch, O. Kättlitz, Intermetallics 19, 757 (2011).

[6] J. Lapin, T. Pelachová, H. Staneková, M. Dománková, Kovove Mater. 48, 337 (2010).

[7] J. Lapin, T. Pelachová, V.T. Witusiewicz, E. Dobročka, Intermetallics 19, 121 (2011).

[8] J. Lapin, Z. Gabalcová, T. Pelachová, O. Bajana, Mater. Sci. Forum 638-642, 1368 (2010).

[9] H. Jiang, K. Zhang, X.J. Hao, H. Saage, N. Wain, D. Hu, M.H. Loretto, X. Wu, Intermetallics 18, 938 (2010).

[10] J. Aguilar, U. Hecht, A. Schievenbusch, Mater. Sci. Forum 638-642, 1275 (2010).

[11] J. Lapin, T. Pelachová, M. Dománková, Intermetallics 19, 819 (2011).

[12] J. Lapin, Intermetallics 14, 115 (2006).

[13] J. Lapin, Scr. Mater. 50, 261 (2004).

[14] F. Appel, R. Wagner, Mater. Sci. Eng. R 22, 187 (1988).

[15] V. Recina, D. Lundström, B. Karlsson, Metall. Mater. Trans. A 33A, 2869 (2002).

[16] J. Lapin, M. Nazmy, Mater. Sci. Eng. A 380, 298 (2004).

[17] T.A. Parthasarathy, M.G. Mendiratta, D.M. Dimiduk, Scr. Mater. 37, 315 (1997).

[18] H. Staneková, J. Lapin, T. Pelachová, Acta Phys. Pol. A 122, 512 (2012).

[19] Y. Mishin, Chr. Herzig, Acta Mater. 48, 589 (2000).

[20] X.W. Du, J. Zhu, Y.W. Kim, Intermetallics 9, 137 (2001). 